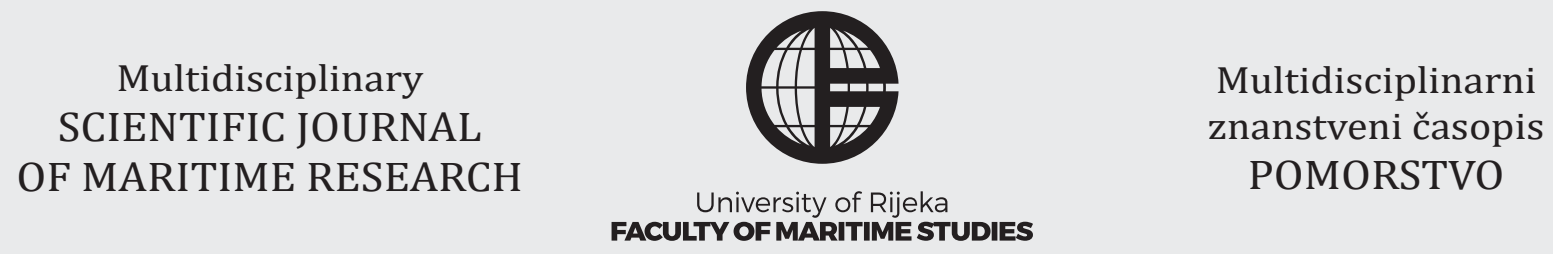

\title{
A Review of Blockchain Technology Implementation in Shipping Industry
}

\author{
Marija Jovićn ${ }^{1}$ Marko Filipović ${ }^{2}$, Edvard Tijan ${ }^{1}$, Mladen Jardas ${ }^{1}$ \\ ${ }^{1}$ University of Rijeka, Faculty of Maritime Studies, Studentska 2, 51000 Rijeka, Croatia, e-mail: jovic@pfri.hr; etijan@pfri.hr; mjardas@pfri.hr \\ ${ }^{2}$ Ul. Braće Cetina 2, 51000 Rijeka, Croatia, e-mail: markofilipovic8@hotmail.com
}

\section{ABSTRACT}

This article presents a comprehensive review of the current and rising trends of blockchain technology usage in shipping industry. The definition and features of blockchain technology are provided, as well as the potential usage of blockchain technology in various areas (financial services, Internet of Things, medicine, government, etc.), in order to better understand its complexity and application. Furthermore, the major challenges of blockchain technology are shown, and the most prominent examples of blockchain applications in shipping industry are provided. The application and advantages of blockchain technology in seaports are demonstrated through several examples.

\section{ARTICLE INFO}

\section{Review article}

Received 13 May 2019

Accepted 6 September 2019

Key words:

Blockchain technology

Shipping industry

Seaports

\section{Introduction}

Maritime transport has been the main mode of transport for global trade over the past centuries and one of the cornerstones of globalization (Halim et al., 2018). Around $90 \%$ of world trading is carried out by the shipping industry (IMO (International Maritime Organization), 2019). Maritime transportation plays a significant role in the integrated transportation system, especially in international trade system (Caban, Ignaciuk and Misztal, 2017).

Blockchain as a relatively new technology can positively affect to maritime transport and it can bring many innovative changes to outmoded industry as it is today. The blockchain is a digital, decentralized and distributed ledger in which transactions are logged and added in chronological order with the goal of creating permanent and tamper-proof records (Treiblmaier, 2019). Blockchain is designed to achieve decentralization, real-time peerto-peer operation, anonymity, transparency, irreversibility and integrity in a widely applicable manner (Tijan, Aksentijević, et al., 2019).

Furthermore, it can positively affect maritime transport as well as all logistic processes, from storage to delivery and payment (Tijan, Aksentijević, et al., 2019). In addition to increased transparency and security achieved through blockchain, it is possible to speed up the physical flow of goods (Lindman, Rossi and Tuunainen, 2017). For example, Maersk and IBM have decided to jointly build their own blockchain solution and the goals are to reduce the cost of global shipping, improving of visibility across supply chains and elimination inefficiencies stemming from paper-based processes (IBM, 2018).

This paper researches the applications of blockchain technology with special emphasis on blockchain technology in maritime transport, providing a better understanding of blockchain technology role in maritime transport sector. The research problem stems from increased costs and lost time due to the archaic or inadequate execution and monitoring of business processes.

The goal of the research is to present the impact of blockchain technology on maritime transport development, as well as to demonstrate the possibilities of using blockchain in shipping industry. The research has been conducted in connection with Activity D3.1.1 of DigLogs project "Collection of the main disruptive innovations that could affect the area in the next five years". The DigLogs project involves cooperation between the two countries - 
Italy and Croatia, and is being implemented with the aim of creating the necessary concepts, technological solutions, models and planning to establish the most advanced digitized logistic processes for multimodal freight traffic and passenger services in the program area.

\section{Blockchain technology}

The blockchain technology is based on a method where previously unknown parties can jointly generate and maintain practically any database on a fully distributed basis where transaction correctness and completeness are validated using consensus of independent verifiers (Tijan, Aksentijević, et al., 2019). Blockchain consists of two terms: the "block" and the "chain". "Block" represents transactions, while "chain" links these transactions into one chain. Block is the basic blockchain unit. Each block contains a list of transactions and links to the previous block in the chain. The principle of blockchain technology is accomplished through a decentralized peer-to-peer network. The peer-to-peer network is defined as a data sharing network between many working units (Peer-to-peer mreže, 2009).

The first blockchain was used as a basis for Bitcoin cryptocurrency in the financial sector. Bitcoin uses peerto-peer technology, and it operates without any trusted third-party authority that may appear as a bank, a chartered accountant, a notary, or any other centralized service (Maersk and IBM to Form Joint Venture Applying Blockchain to Improve Global Trade and Digitize Supply Chains, 2018). Bitcoin is open-source; its design is public, nobody owns or controls (Bitcoin, 2019). Moreover, it is a cryptographically secure electronic payment system, and it enables transactions involving virtual currency in the form of digital tokens called Bitcoin (BTC or bitcoins) (Conti et al., 2018). In the shipping industry, blockchain was initially used to enable confidential financial transactions between the stakeholders, without relying on "third parties". However, there is a difference between public blockchain networks, and solutions which are present in shipping industry. Public blockchain allow anyone to join, no one has control over the networks etc. (Public Vs Private Blockchain In A Nutshell, 2018), while the last are typically based on permissioned blockchains which have very different properties and are much more similar to traditional information systems or database.

Blockchain-based smart contract represents a distributed operating system (Uvod u blockchain - Ethereum $i$ pametni ugovori - startit, 2017). A smart contract can be defined as a self-executing pre-evaluated contract (Allam, 2019). A smart contract aims to digitally facilitate, verify, or enforce the negotiation or performance of a contract (Mourouzis and Tandon, 2019). Blockchain technology includes several preventive mechanisms (e.g., distributed consensus and cryptography) to reduce risks of cyberattacks. Blockchain can be applied in diverse applications from financial assets, payment systems, smart contracts, operational risk in financial market, risk management, Internet of Things (IoT) to public and social services (Tijan, Aksentijević, et al., 2019). IoT technology may be improved by blockchain technologies. The Internet of Things represents the digital, or "smart" connection of objects using RFID sensors, Wi-Fi, Bluetooth and other "smart" protocols in order to accelerate business processes (Jović et al., 2019). The typical applications of IoT include logistics management with Radio-Frequency Identification (RFID) technology, smart homes, e-health, smart grids, the maritime industry, etc (Tijan, Aksentijević, et al., 2019).

There is a difference between blockchain and other smart technologies. For example, Blockchain is designed as a basis for applications that involve transaction and interactions. These can include smart contracts (smart contracts are automatically carried out when a specific condition is met, for instance regarding the conditions of goods or environmental conditions) or other smart applications that support specific Internet of Things processes. In this way, blockchain technology can improve not just compliance in the IoT but also IoT features and cost-efficiency (i-SCOOP, 2018).

\section{Blockchain challenges}

Blockchain technology is still very immature, there is no single underlying standard, concepts are difficult to be mastered and there is need for programming intervention even in the simplest forms of implementation (Tijan, Aksentijević, et al., 2019). Furthermore, lack of regulation creates insecurity, because some facets of smart contract technology might be adopted by the logistics market, just to be overregulated, or even to be considered illegal (Gatteschi et al., 2018).

Blockchain technology suffers from scalability and performance issues: all nodes in the chain must process all transactions, and this presents an issue with large and especially global scale roll-outs (Tijan, Aksentijević, et al., 2019). Therefore, "the technology is very energy intensive, and proof calculations expend significant amounts of processor power. Furthermore, users' privacy might be reduced, because all nodes contain a full copy of the ledger, and there is no central authority to contact in case of evident security breach" (Tijan, Aksentijević, et al., 2019).

Distributed trust and therefore security and privacy are at the core of the blockchain technologies, and have the potential to either make them a success or cause them to fail (Karame and Capkun, 2018). Personal data, and sensitive data in general, should not be trusted in the hands of third-parties, where they are susceptible to attacks and misuse (Zyskind, Nathan and Sandy' Pentland, 2015). Instead, users should own and control their data without compromising security or limiting companies' and authorities' ability to provide personalized services. One of the solutions is a platform which will combine a blockchain, re-purposed as an access-control moderator, with an off- 
blockchain storage solution (Laurent et al., 2018). Users do not have to trust third parties and are always aware of the data that is being collected about them and how it is used. In addition, the blockchain recognizes the users as the owners of their personal data. Companies, in turn, can focus on utilizing data without being overly concerned about properly securing and compartmentalizing them.

The Deloitte US and global blockchain practices commissioned the survey "Deloitte's 2018 global blockchain survey" in March and April 2018, primarily as a research vehicle to gain greater insights into the overall attitudes and investments in blockchain as a technology (Deloitte, 2018). Despite the aforementioned challenges regarding the security, according to the survey, the majority of respondents (1053 globally) believe that blockchain is more secure than conventional IT systems.

\section{The application of blockchain technology in shipping industry}

The maritime industry is part of a complex and information-intensive maritime supply chain comprising a set of organizations that are globally connected and distributed, including other critical infrastructures that support world trade, such as transport and port structures (Gausdal, Czachorowski and Solesvik, 2018). The maritime industry lacks innovations related to operations procedures and logistics, and one of the most promising areas of maritime innovation is related to digitalization, including the development of smart ships, smart fleet and smart global logistics (Tijan, Aksentijević, et al., 2019), (Wang et al., 2016).

Although the maritime industry is technologically advanced, innovations in the maritime sector have been primarily related to ship construction and propulsion, oil and gas exploration, seabed exploitation technologies, and other-mainly engineering-based-innovations (Tijan, Aksentijević, et al., 2019). The following are some of the most prominent examples of blockchain applications in maritime industry, with the emphasis on maritime transport.

\section{TradeLens - Maersk and IBM blockchain}

Maersk and IBM joined together in order to develop a blockchain solution aimed at digitalizing global trade, and they called it "Tradelens". Furthermore, inspired by this initiative, other established industry actors have also begun to form their own partnerships or to join industry wide consortiums hoping to reach the promised benefits of blockchain technology. According to IBM, the joint blockchain initiative had the potential to "vastly reduce the cost and complexity of trading" (Maersk and IBM Unveil First Industry-Wide Cross-Border Supply Chain Solution on Blockchain, 2017). Figure 1 shows the Maersk and IBM blockchain solution for digitalizing global trade (IBMBlockchain, 2018).

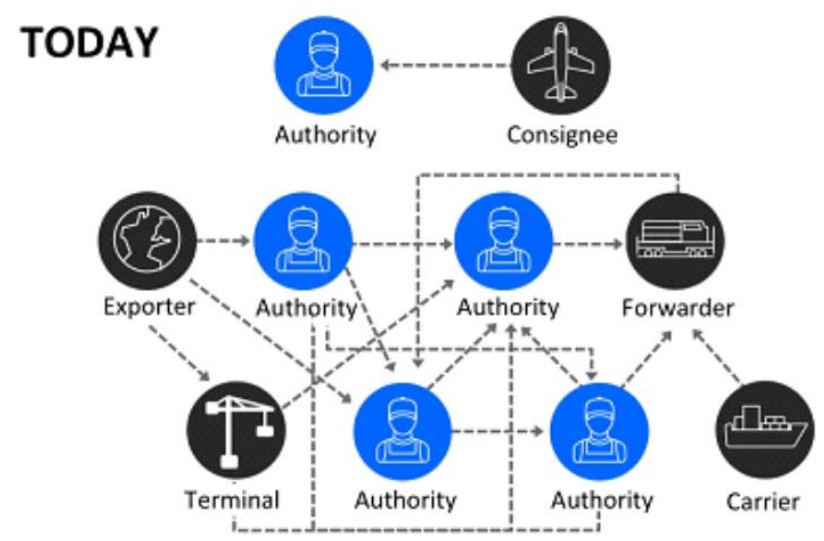

\section{FUTURE}

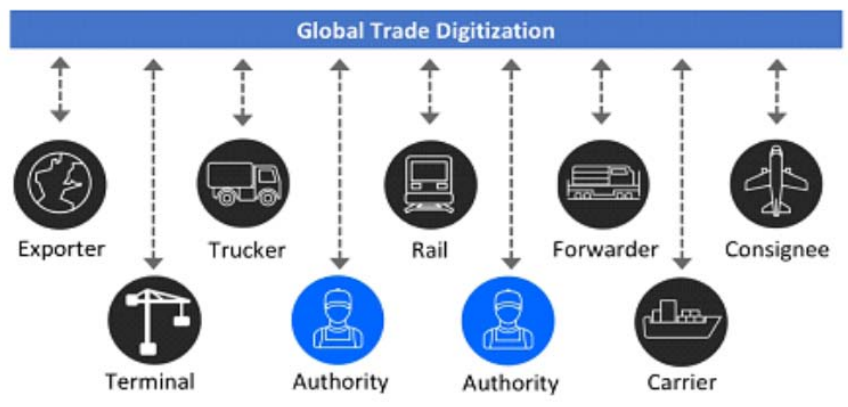

Figure 1 Maersk and IBM blockchain solution for digitalizing global trade (IBM-Blockchain, 2018)

The processes involving international shipments of goods by sea are complex since they involve a large number of organisations and people, including a network of shippers, freight forwarders, ocean carriers, ports, and customs authorities. With the ability to monitor the cargo, the platform will reduce the need for documentation, and automated paperwork will enable safe sending and signing of contracts using blockchain technology. Blockchainbased smart contract will have a significant role in the Maersk platform as it enables managing approvals, faster processing of information compared to the current system, and the number of errors will be reduced to zero (Shipping Blockchain: Maersk Spin-Off Aims to Commercialize Trade Platform - CoinDesk, 2018).

\section{BDTS - CargoX}

CargoX developed a BDTS platform (Blockchain Documentation Transaction System). BDTS presents a platform with many applications where Smart $\mathrm{B} / \mathrm{L}^{\mathrm{TM}}$ is the most popular one. CargoX is the independent supplier of blockchain documentation transaction system which provide an extremely fast, safe, reliable, and cost-effective way to process shipping documents anywhere in the world (CargoX / Reshaping the Future of Global Trade with the World's First Blockchain Bill of Lading, 2019). CargoX has created an open system based on blockchain technology and encrypted decentralized data storage that will enable the creation and exchange of traffic-related documents by smart contracts. 


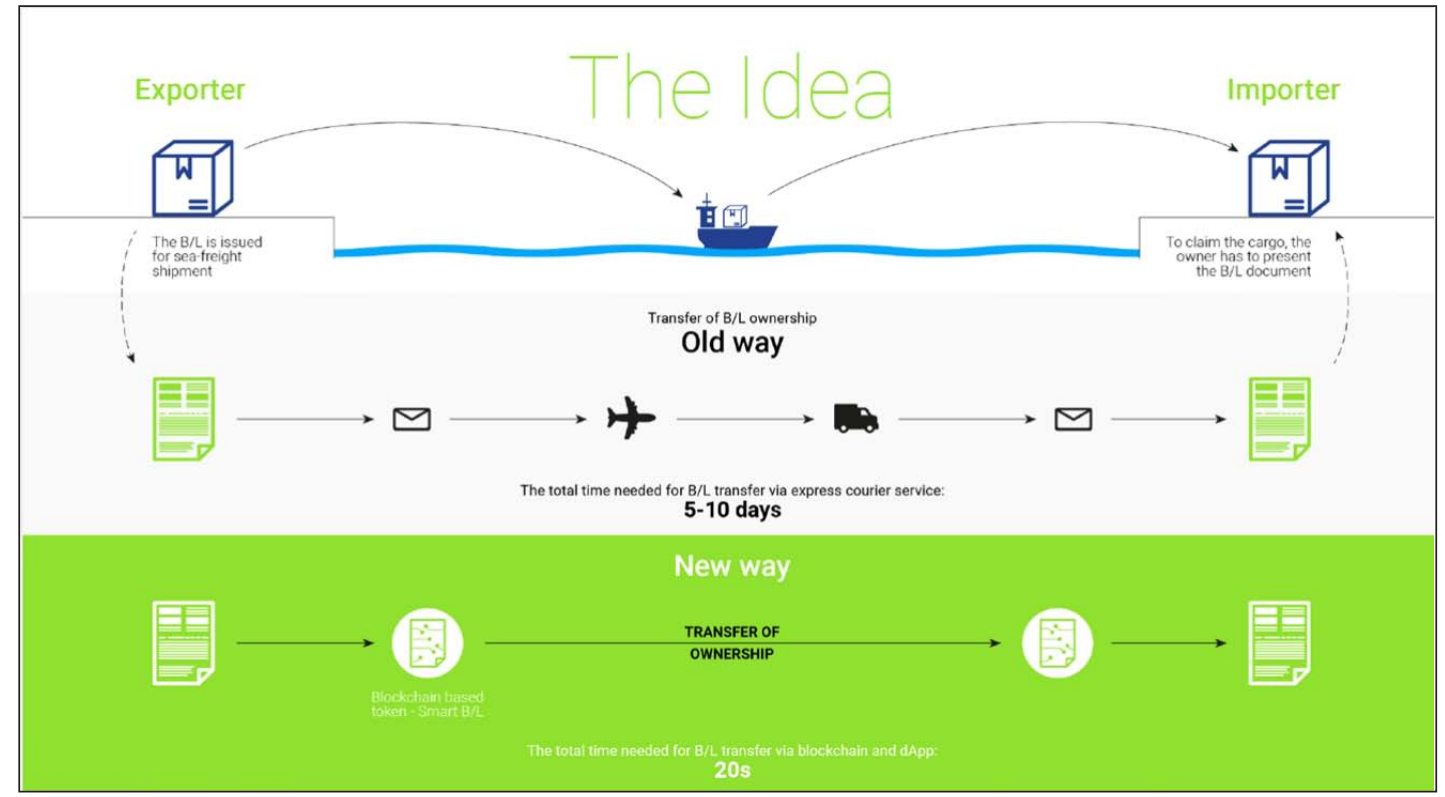

Figure 2 Comparison between paper solution and CargoX digital solution (From the Past to the Future, 2019)

With Smart B/L application, CargoX aims to substitute today's physical (paper based) proof of ownership (used to prove ownership of the cargo at the destination port) with the digital proof of ownership, making the Bill of Lading safer, immediately portable, easier to archive and much cheaper than the current Bill of Lading in paper form. Figure 2 shows the comparison between current work flow and work flow provided from CargoX Smart B/L $\mathrm{L}^{\mathrm{TM}}$ blockchain based solution for transferring documents in less than 20 seconds (From the Past to the Future, 2019).

CargoX aims to connect issuers, carriers, importers, exporters and other stakeholders in a balanced system based on trust and interaction. In this respect, CargoX's goal is to eliminate the need for an intermediary by providing tools for secure document sharing, significantly reducing costs and time of delivery by offering a high level of security and transparency.

Port of Koper presents a good example of successful implementation of blockchain technology. In August 2018, the first ever container processed with the revolutionary new blockchain-based CargoX Smart Bill of Lading ${ }^{\mathrm{TM}}$ was released in the aforementioned port. The Bill of Lading for this shipment has been issued electronically and transferred with the help of an ultra-secure and reliable public blockchain network in just minutes instead of days or weeks, and the chances of loss, theft or damage to the Bill of Lading have been dramatically reduced to near-zero ( 7 Major Blockchain Technology Developments In Maritime Industry In 2018, 2019).

Blockchain platform for global monitoring of goods ShipChain

ShipChain was established to address the problems facing the logistics industry. The solution offered by ShipChain requires the deployment of blockchain technology, which is based on the entire information delivery chain to the end user - from the moment the product leaves the factory, field etc. - to the receiving customer via a "trust less" system and transparent blockchain contracts (ShipChain: The Logistics Platform Powered by Blockchain, 2018).

With the support of the ShipChain platform, there will be a possibility of monitoring cargo and status points globally, i.e. on all geographic points. Each point will be encrypted and available for interpreting and only involved stakeholders will see all the cargo data. Carriers will have more visibility through their supply chain and will communicate easily. Information on loads, geographic points, and basic compliance information will be recorded and publicly validated within the "sidechain" (S\&amp;R-Shipchain-Outline Content Breakdown, 2017). A sidechain is a separate blockchain that is attached to its parent blockchain using a two-way peg (What are Sidechains? - Hacker Noon, 2018). The two-way peg enables interchangeability of assets at a predetermined rate between the parent blockchain and the sidechain (What are Sidechains? - Hacker Noon, 2018). The contract will be completed and recorded on the main blockchain after delivery and receipt of the cargo (ShipChain, 2018).

The features of ShipChain may be summarized as follows (Shipchain, 2019):

1. Visibility - unified solution for asset tracking (a single platform from shipment to delivery)

2. Trust - transparency through immutability (data storage that cannot be changed, which is approved by all participants)

3. Control - thanks to secure ShipChain Vaults, business owners have complete control over who \& how their data is queried. 
Morpheus network

Morpheus Network is a full-service, global, automated, supply chain platform with an integrated payment system utilizing blockchain technology (Morpheus.Network - Disrupt Global Trade, 2019). Any errors in the documentation may destroy the entire consignment or create additional costs for stakeholders. Several stakeholders (importers, exporters, shippers, customs brokers, terminal operators etc.) use numerous maritime documentations. Such documentation must be reviewed by the aforementioned parties and forwarded to a next location. Morpheus Network aims to simplify the described process and make it more effective. Every time a document must be shared among multiple institutions, placing that record on the blockchain enables real-time updates that can be seen but not changed. This will enable significant savings of both time and cost, while at the same time ensuring a high level of trust (Morpheus.Network - Disrupt Global Trade, 2019).

\section{Global Shared Container Platform}

The company Blockshipping created the "Global Shared Container Platform" (GSCP), a platform for more manageable handling of containers and solving some of the most important problems of containerization in shipping. Figure 3 shows workflow of GSCP platform (ICO Review -5 reasons why Blockshipping should be revolution the Global Container Shippin Industry, 2018).

The GSCP platform aims to become the main IoT (Internet of Things) platform for the shipping industry.
Blockchain technology provides full transparency as the GSCP platform enables operations within a large number of stakeholders in the maritime industry in order to achieve significant cost savings (Blockshipping's GSCP ICO - Transforming The Global Container Shipping Industry, 2019).

Seaports are important nodes in the intermodal transport and numerous stakeholders operate in the complex seaport environment, (shipping companies, port authorities, terminal operators, freight brokers etc.) (Tijan, Jović, et al., 2019). In an optimal situation, all information related to the cargo are available to all relevant stakeholders, creating a digitalized connection. Each seaport which aims to be competitive should accept digitalization which enables transparency and smoother data exchange. However, the prerequisite for the blockchain implementation is stakeholder connectivity.

Blockchain is definitely one of the most discussed topics in the recent years and could have a tremendous impact on the future of logistics and port digitalisation (The Blockchain Potential for Port Logistics / KennisDC Logistiek, 2017). One of the seaports that showed large interest in digitalizing and using blockchain is the port of Rotterdam. BlockLab (News - Blocklab, 2019) (a subsidiary of the Port of Rotterdam, co-founded by the City of Rotterdam) has built an application relying on blockchain software which can securely track the ownership and location of cargo shipments: on average, 28 distinct parties are involved in any single freight logistics transaction; with documents containing potentially sensitive data on the shipment

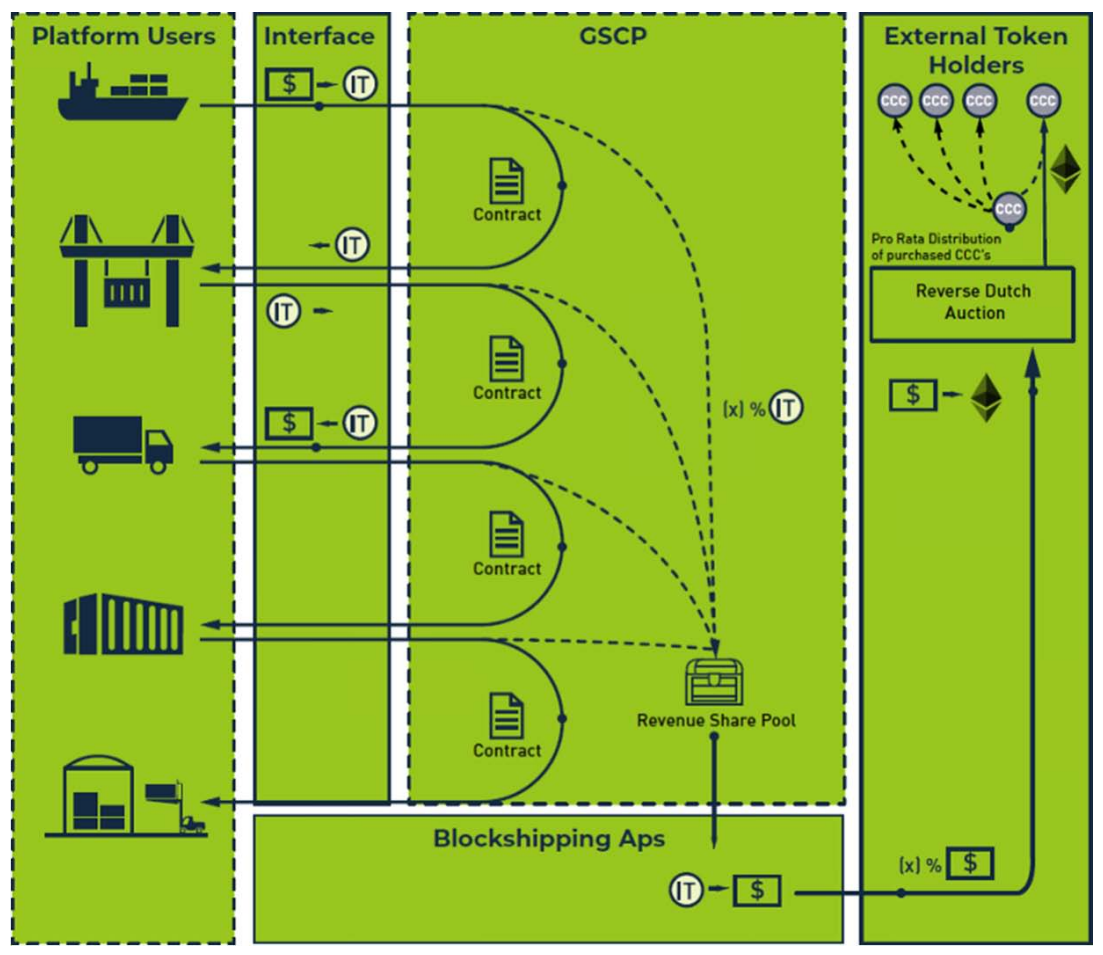

Figure 3 GSCP platform (ICO Review - 5 reasons why Blockshipping should be revolution the Global Container Shippin Industry, 2018) 
changing hands up to 200 times between its being dispatched and its final delivery (Port of Rotterdam blockchain solutions begin deployment, 2019).

Blockchain technology can connect stakeholders that were not previously associated, enable new forms of collaboration, and create new business opportunities. In logistics, blockchain has the potential to transform port processes by documenting, validating and securing each event in the chain (The Blockchain Potential for Port Logistics / KennisDC Logistiek, 2017).

Through its typical features, blockchain can add value to port logistics and port digitalization in numerous ways (An explorative study on blockchain technology in application to port logistics / KennisDC Logistiek, 2018). Therefore, according to KennisDC Logistiek, these are related to building trust, provision of secure data, visibility, network expansion and integration of supply flows (The Blockchain Potential for Port Logistics / KennisDC Logistiek, 2017).
According to Oude Weernink et al. (2017), blockchain in seaports can be used in several ways, such as (Oude Weernink et al., 2017):

\section{Current exchange of information in seaports}

When the carrier enters the port, the cargo documentation is generally processed by the ship's agent and sent to the PCS - "Port Community System". Figure 4 shows current information flow in the import carrier process (Oude Weernink et al., 2017).

PCS allows the distribution of information between the stakeholders in the network to facilitate the movement of containers throughout the process. not all the parties involved are included in the network (insurance companies, banks, etc.). This process has inefficient means of communication, leaving enough space for improvements that a blockchain can accomplish.

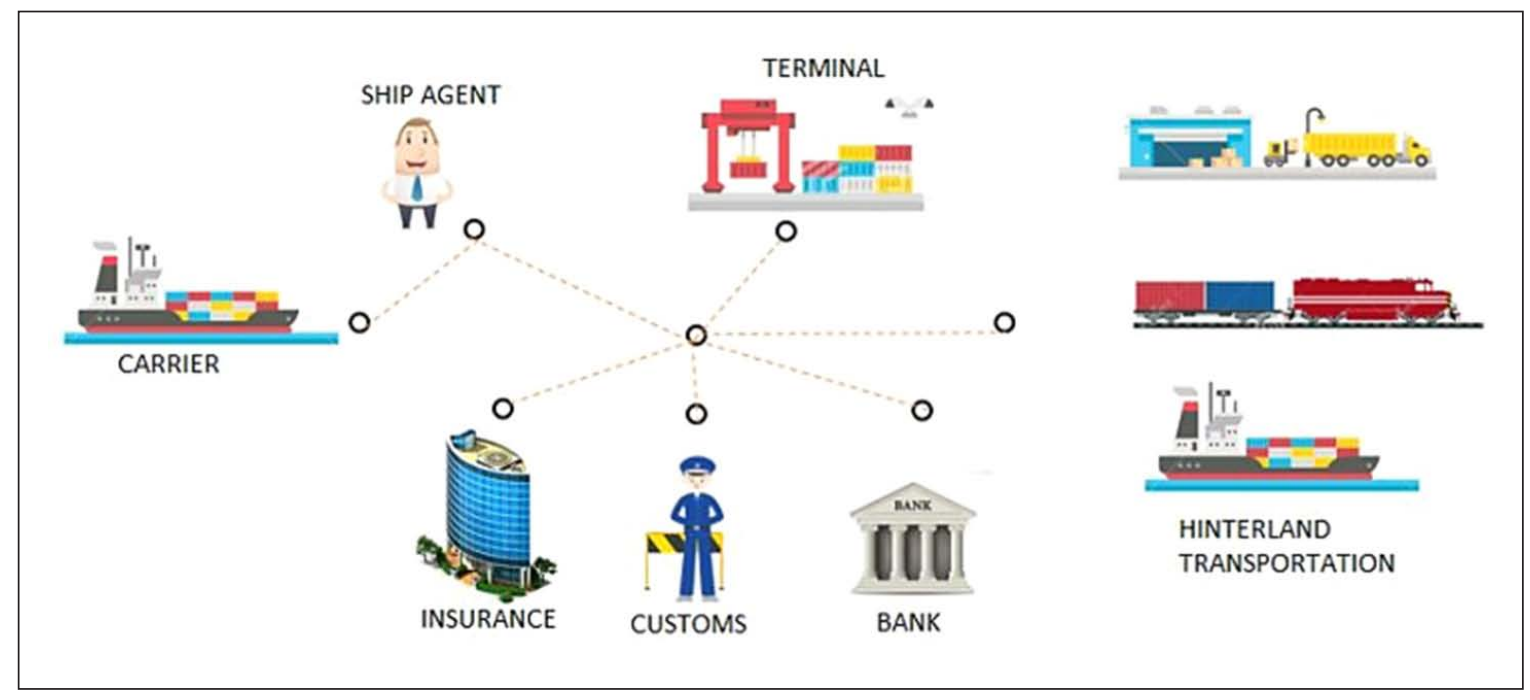

Figure 4 Current information flow in the import carrier process (Oude Weernink et al., 2017)

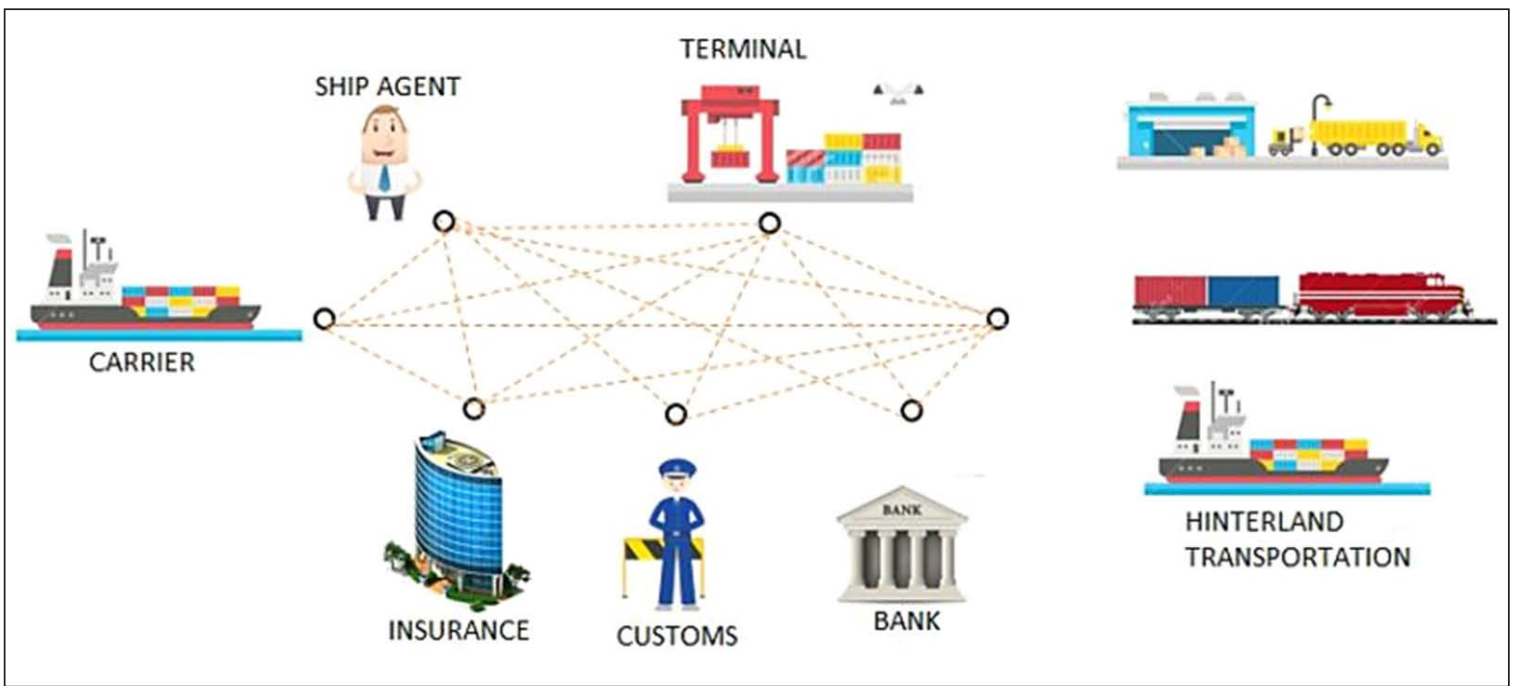

Figure 5 Blockchain information flow in the import carrier process (Oude Weernink et al., 2017) 
2. Information flow in seaports with the support of blockchain technology

Blockchain implementation may facilitate the exchange of information between parties involved in the process. This can be achieved by storing the cargo information on the ledger. Figure 5 shows blockchain information flow in the import carrier process (Oude Weernink et al., 2017).

Instead of exchanging documentation, stakeholders involved in the process are granted permission to access the blocks where the data are stored. This leads to the creation of a unique, shared piece of information that can be accessed in real-time and with lower transaction costs. The process can be further accelerated by involving stakeholders who are currently external of the process (banks, insurance companies).

3. Blockchain application in all segments of seaport operations

The database can be further enhanced by implementing the Internet of Things (IoT) device by connecting them as blockchain nodes. For example, trackers can be mounted on containers so the sensor signals can automatically record data on the blockchain without any user input. Moreover, sensors installed in the container can monitor the status of the goods, providing information to the insurance company. Furthermore, by connecting smart devices, it is also possible to fully automate the process.

\section{Discussion}

Blockchain is certainly one of the most widely debated topics recently, and could have a lasting effect on the future of shipping industry. In this research, business processes that are part of shipping industry were identified and the current state of blockchain technology was ana- lysed. The research was conducted by collecting the most prominent ways of using blockchain technology in shipping industry, with the emphasis on maritime transport, in order to determine the direction in which the blockchain technology is developing.

The impact of blockchain technology in shipping industry may definitely be considered positive, according to the examples researched. As mentioned before, blockchain implementation in shipping industry faces certain challenges or risks (Tijan, Aksentijević, et al., 2019), (Gatteschi et al., 2018), (Karame and Capkun, 2018), (Zyskind, Nathan and Sandy' Pentland, 2015) which should be minimized in order to fully exploit the aforementioned advantages (Figure 6).

One of the challenges Blockchain technology faces is the lack of standards, because not all stakeholders are looking to implement similar blockchain solutions and platforms. As a result, an interoperability issue may arise.

Although blockchain technology offers an innovative platform for a new decentralized and transparent transaction mechanism in industry and business (Abeyratne and Monfared, 2016), it is still very immature. Numerous trials and blockchain pilot projects exist globally but they are now primarily linked to smaller groups i.e. participants in the industry (Maersk, IBM) who have started to establish their own alliances in order to achieve the advantages of Blockchain technology. Nevertheless, the successful projects will probably experience a fast expansion in shipping industry and in overall transportation chain as well. Various experts consider that successful blockchain implementation is possible only if all stakeholders are involved in the process, such as shipping lines, terminal operators, manufacturers, banks, insurers, brokers and port authorities. As long as blockchain technology exists only in a limited area within the smaller pilot projects, benefits of Blockchain technology (e.g. reducing time of document processing) will not be fully exploited. In this respect,

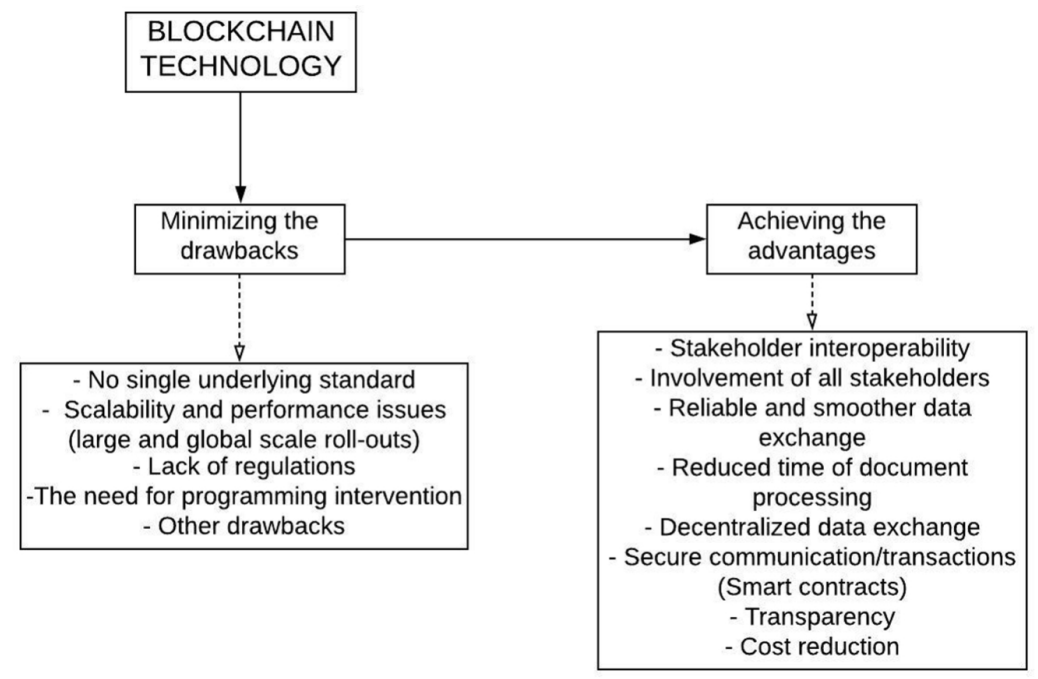

Figure 6 Blockchain advantages after minimizing the drawbacks 
one of the main advantages of Blockchain technology is reducing the need for paper documents. Global shipping industry, especially maritime transport still involves a large number of paper documents, prolonging the time for processing the data and any step that enhances the current state might have significant effects for the whole sector. Blockchain can in this case register all the document changes and provide visibility of their location to all other interested parties. Openly accessible distributed blockchains that are not proprietary to one company can guarantee that nobody can easily forge the paper trail.

Positive aspects of Blockchain could actually change the whole shipping industry and overall trading processes if the risks associated with Blockchain are correctly mitigated. According to World Economic Forum, Blockchain could boost trade by more than $\$ 1$ trillion in the next 10 years by mitigating risks, removing barriers and streamlining trading processes (World Economic Forum, 2018).

\section{Conclusion}

Blockchain technology is a digital and distributed ledger which enables decentralization, real-time peer-to-peer operation, transparency etc. It is based on a method by which previously unknown parties can jointly generate and maintain almost any database on a fully distributed basis.

Blockchain technology is a potential solution to numerous problems such as: insufficient availability of cargo monitoring (maritime transport involves many stakeholders) and lack of transparency (resulting from poor data handling), relying on paperwork in $21^{\text {st }}$ century, etc. In this respect, Maersk and IBM developed their blockchain solution: the need for documentation will be reduced, and automated paperwork will enable safe sending and signing of contracts via blockchain technology. Another example of blockchain usage in maritime transport is an open system based on blockchain technology and encrypted decentralized data storage created by CargoX. The goal is to connect stakeholders such as issuers, carriers, importers, and exporters in a balanced system based on trust and interaction by using their BDTS platform.

Each seaport, as a part of maritime transport, which aims to be competitive should accept digitalization. Blockchain could have a tremendous impact on the future of port digitalisation. One of the seaports that showed large interest in digitalizing and using blockchain is the port of Rotterdam which has developed an application relying on blockchain software in order to securely track the ownership and location of cargo shipments.

Although blockchain technology provides numerous advantages, the disadvantage is the absence of a single underlying standard. Furthermore, concepts are difficult to be mastered and programming intervention are necessary even in the simplest forms of implementation. Furthermore, all nodes in the chain must process all transactions, and this presents an issue with large and especially global scale rollouts. Nevertheless, the blockchain technology possesses huge potential for development and further improvements in maritime transport.

\section{Acknowledgments}

This work was supported by "DigLogs - Digitalising Logistics Processes" (Interreg V-A Italy - Croatia 20142020) project.

\section{References}

[1] 7 Major Blockchain Technology Developments in Maritime Industry in 2018 (2019). Available at: https://www.marineinsight.com/know-more/7-major-blockchain-technologydevelopments-in-maritime-industry-in-2018/ (Accessed: 5 July 2019).

[2] Abeyratne, S. and Monfared, R. (2016) 'Blockchain Ready Manufacturing Supply Chain Using Distributed Ledger', International Journal of Research in Engineering and Technology, 05(09), pp. 1-10. doi: 10.15623/ijret.2016.0509001.

[3] Allam, Z. (2019) 'On Smart Contracts and Organisational Performance: A Review of Smart Contracts through the Blockchain Technology', Review of Economic and Business Studies, 11(2), pp. 137-156. doi: 10.1515/rebs-2018-0079.

[4] An explorative study on blockchain technology in application to port logistics / KennisDC Logistiek (2018). Available at: http://www.kennisdclogistiek.nl/publicaties/an-explorative-study-on-blockchain-technology-in-application-toport-logistics (Accessed: 23 April 2019).

[5] Bitcoin (2019). Available at: https://bitcoin.org/ (Accessed: 2 May 2019).

[6] Blockshipping's GSCP ICO - Transforming the Global Container Shipping Industry (2019). Available at: https://www. blockshipping.io/ (Accessed: 24 April 2019).

[7] Caban, J., Ignaciuk, P. and Misztal, W. (2017) 'Safety of Maritime Transport in the Baltic Sea', in MATEC Web of Conferences: 18th International Scientific Conference - LOGI 2017. České Budějovice, Czech Republic: EDP Sciences, pp. 1-8. doi: 10.1051/matecconf/201713400003.

[8] CargoX / Reshaping the Future of Global Trade with the World's First Blockchain Bill of Lading (2019). Available at: https://cargox.io/ (Accessed: 26 April 2019).

[9] Conti, M. et al. (2018) 'A Survey on Security and Privacy Issues of Bitcoin', IEEE Communications Surveys \& Tutorials, 20(4), pp. 3416-3452. doi: 10.1109/COMST.2018.2842460.

[10] Deloitte (2018) Breaking blockchain open Deloitte's 2018 global blockchain survey. Available at: https://www2. deloitte.com/content/dam/Deloitte/cz/Documents/financial-services/cz-2018-deloitte-global-blockchain-survey. pdf (Accessed: 3 May 2019).

[11] From the Past to the Future (2019). Available at: https:// cargox.io/welcome/ (Accessed: 5 July 2019).

[12] Gatteschi, V. et al. (2018) 'Blockchain and Smart Contracts for Insurance: Is the Technology Mature Enough?', MDPI: Future Internet 2018, 10(6), pp. 8-13. doi: 10.3390/fi10020020.

[13] Gausdal, A. H., Czachorowski, K. V. and Solesvik, M. Z. (2018) 'Applying Blockchain Technology: Evidence from Norwegian Companies', MDPI Sustainability, 10(6), pp. 1-16. doi: $10.3390 /$ su10061985. 
[14] Halim, R. A. et al. (2018) 'Decarbonization Pathways for International Maritime Transport: A Model-Based Policy Impact Assessment', MDPI Sustainability, 10(7). doi: 10.3390/ su10072243.

[15] i-SCOOP (2018) Blockchain and the Internet of Things: the IoT blockchain opportunity and challenge. Available at: https://www.i-scoop.eu/blockchain-distributed-ledger-technology/blockchain-iot/ (Accessed: 15 July 2019).

[16] IBM- Blockchain (2018). Available at: https://www.ibm. com/blogs/blockchain/wp-content/uploads/2018/01/ GTD-Overview-Image2-e1516060395602-1024x443.png (Accessed: 7 May 2019).

[17] IBM (2018) TradeLens: How IBM and Maersk Are Sharing Blockchain to Build a Global Trade Platform - THINK Blog. Available at: https://www.ibm.com/blogs/think/2018/11/ tradelens-how-ibm-and-maersk-are-sharing-blockchain-tobuild-a-global-trade-platform/ (Accessed: 23 April 2019).

[18] ICO Review - 5 reasons why Blockshipping should be revolution the Global Container Shipping Industry (2018). Available at: https://medium.com/biomanforcerose/ico-review-5-reasons-why-blockshipping-should-be-revolution-the-globalcontainer-shipping-be18595c6933 (Accessed: 7 May 2019).

[19] IMO (International Maritime Organization) (2019). Available at: https://business.un.org/en/entities/13 (Accessed: 2 May 2019).

[20] Jović, M. et al. (2019) 'An Overview of Security Challenges Of Seaport IoT Systems', in 42nd International Convention on Information and Communication Technology, Electronics and Microelectronics (MIPRO). Opatija, Croatia: MIPRO Proceedings Digital Economy/Digital Society 2019. Available at: https://bib.irb.hr/prikazi-rad?rad=986080.

[21] Karame, G. and Capkun, S. (2018) 'Blockchain Security and Privacy', IEEE Security \& Privacy, 16(4), pp. 11-12. doi: 10.1109/MSP.2018.3111241.

[22] Laurent, M. et al. (2018) 'A Blockchain based Access Control Scheme', in 15th International Conference on Security and Cryptography (SECRYPT 2018). Porto, Portugal, pp. 168176. doi: $10.5220 / 0006855601680176$.

[23] Lindman, J., Rossi, M. and Tuunainen, V. (2017) 'Opportunities and risks of Blockchain Technologies in payments - a research agenda', in Proceedings of the 50th Hawaii International Conference on System Sciences. Aalto University Research information portal. doi: 10.24251/HICSS.2017.185.

[24] Maersk and IBM to Form Joint Venture Applying Blockchain to Improve Global Trade and Digitize Supply Chains (2018). Available at: https://www-03.ibm.com/press/us/en/pressrelease/53602.wss (Accessed: 2 May 2019).

[25] Maersk and IBM Unveil First Industry-Wide Cross-Border Supply Chain Solution on Blockchain (2017). Available at: https://www-03.ibm.com/press/us/en/pressrelease/51712. wss (Accessed: 3 May 2019).

[26] Morpheus.Network - Disrupt Global Trade (2019). Available at: https://morpheus.network/ (Accessed: 26 April 2019).

[27] Mourouzis, T. and Tandon, J. (2019) Introduction to Decentralization and Smart Contracts. Available at: http://arxiv. org/abs/1903.04806 (Accessed: 29 April 2019).

[28] News - Blocklab (2019). Available at: http://www.blocklab. nl/news / (Accessed: 3 May 2019).

[29] Oude Weernink, M. et al. (2017) 'The Blockchain Potential for Port Logistics', Erasmus University and The Delft University of Technology, (2 January 2018), p. 16. Available at: http://smart-port.nl/wp-content/uploads/2017/06/Bijlage-6_White-Paper-Blockchain.pdf.
[30] Peer-to-peer mreže (2009). Available at: https://www.cis. hr/www.edicija/Peer-to-peermree.html (Accessed: 29 April 2019).

[31] Port of Rotterdam blockchain solutions begin deployment (2019). Available at: https://www.governmenteuropa.eu/ port-of-rotterdam-blockchain/93106/ (Accessed: 3 May 2019).

[32] Public Vs Private Blockchain In A Nutshell (2018). Available at: https://medium.com/coinmonks/public-vs-private-blockchain-in-a-nutshell-c9fe284fa39f (Accessed: 2 May 2019).

[33] S\&amp;R-Shipchain-Outline Content Breakdown (2017). Available at: https://static1.squarespace.com/static/ 5b58858a710699d85d651e42/t/5b65b09c1ae6cf3410eeb de7/1533391031469/S\%26R-\%2BShipchain-\%2BOutline. pdf (Accessed: 26 April 2019).

[34] ShipChain: The Logistics Platform Powered by Blockchain (2018). Available at: https://hacked.com/shipchain-the-logistics-platform-of-the-future/ (Accessed: 26 April 2019).

[35] Shipchain (2019). Available at: https://shipchain.io/ (Accessed: 24 April 2019).

[36] ShipChain (2018). Available at: https://shipchain.io/ (Accessed: 24 April 2019).

[37] Shipping Blockchain: Maersk Spin-Off Aims to Commercialize Trade Platform - CoinDesk (2018). Available at: https:// www.coindesk.com/shipping-blockchain-maersk-spin-offaims-commercialize-trade-platform (Accessed: 24 April 2019).

[38] The Blockchain Potential for Port Logistics / KennisDC Logistiek (2017). Available at: http://www.kennisdclogistiek. $\mathrm{nl} /$ publicaties/the-blockchain-potential-for-port-logistics (Accessed: 23 April 2019).

[39] Tijan, E., Aksentijević, S., et al. (2019) 'Blockchain technology implementation in logistics', MDPI-Sustainability (Switzerland), 11(4). doi: 10.3390/su11041185.

[40] Tijan, E., Jović, M., et al. (2019) The Single Window concept in international trade, transport and seaports, Pomorstvo: scientific journal of maritime research. Available at: https:// www.bib.irb.hr/993505 (Accessed: 7 May 2019).

[41] Treiblmaier, H. (2019) 'Combining Blockchain Technology and the Physical Internet to Achieve Triple Bottom Line Sustainability: A Comprehensive Research Agenda for Modern Logistics and Supply Chain Management', MDPI-Logistics, 3(1), p. 10. doi: 10.3390/logistics3010010.

[42] Uvod u blockchain - Ethereum i pametni ugovori - startit (2017). Available at: https://startit.rs/uvod-u-blockchainethereum-i-pametni-ugovori/ (Accessed: 26 April 2019).

[43] Wang, H. et al. (2016) 'Big data and industrial Internet of Things for the maritime industry in Northwestern Norway', IEEE Region 10 Annual International Conference, Proceedings/TENCON, 2016-Janua (November). doi: 10.1109/TENCON.2015.7372918.

[44] What are Sidechains? - Hacker Noon (2018). Available at: https://hackernoon.com/what-are-sidechains-1c45ea2daf3 (Accessed: 29 April 2019).

[45] World Economic Forum (2018) Blockchain could boost global trade by $\$ 1$ trillion. Available at: https://www.weforum. org/agenda/2018/09/blockchain-set-to-increase-globaltrade-by-1-trillion/ (Accessed: 5 July 2019).

[46] Zyskind, G., Nathan, O. and Sandy' Pentland, A.' (2015) 'Decentralizing Privacy: Using Blockchain to Protect Personal Data', IEEE Security and Privacy Workshops. doi: 10.1109/ SPW.2015.27. 